\title{
Bilateral ankyloblepharon filiforme adnatum associated with cardiac defects:
}

\section{A case report}

\author{
Ling Zhu, Rong Ju
}

Department of Neonatology, Chengdu Women and Children's Central Hospital, Chengdu, China

\section{CASE STUDY}

Please cite this paper as: Zhu L, Ju R. Bilateral ankyloblepharon filiforme adnatum associated with cardiac defects: A case report. AMJ 2018;11(1):34-36. https://doi.org/10.21767/AMJ.2017.3297

\section{Corresponding Author:}

Ling Zhu

Department of Neonatology, Chengdu Women and Children's Central Hospital, No. 1617, Riyue avenue, Qingyang district, Chengdu, 610031 China.

Email: lingzhuchina@126.com

\section{ABSTRACT}

Ankyloblepharon filiforme adnatum (AFA) is a rare congenital anomaly and its presentation always indicates the possibility of other important anomalies. AFA is classified into four subgroups based on the associated abnormalities. Here we report a case of AFA associated with cardiac defects happened to an in vitro fertilization (IVF) female baby whose mother is elderly parturient (more than 43- year-old), and the baby was treated one day after birth.

\section{Key Words}

Ankyloblepharon filiforme adnatum, abnormality, cardiac defects

\section{Implications for Practice:}

\section{What is known about this subject?}

Ankyloblepharon Filiforme Adnatum is rare congenital anomaly. It often was associated with some other abnormalities.

\section{What new information is offered in this case study?}

AFA is often an isolated manifestation, but this newborn presented AFA associated with congenital heart disease, which is considered as a subgroup of AFA.

3. What are the implications for research, policy, or practice?

The newborn with AFA should be had fully physical examination to find out other anomalies.

\section{Background}

Ankyloblepharon filiforme adnatum (AFA) is defined as a thin tissue of bands partially or completely connecting the upper and lower eyelids. Hasner first reported a case with AFA in 1881, and then more and more AFA cases were reported in different countries. It is a rare benign congenital anomaly with an incidence of 4.4 per 100,000 newborns. It sporadically occurred in different regions or races, especially in Indian and Caucasian ethnicity. Here we report a case of bilateral AFA associated with cardiac defects happened to IVF female baby.

\section{Case details}

A female IVF 39+2 weeks baby with a birth weight of $3080 \mathrm{~g}$ was delivered by caesarean section due to intrahepatic cholestasis of pregnancy on April 10, 2017 in our hospital. Apgar score was 9, 9, and 10 at 1st, 5th and 10th minute, respectively. Several hours later, the initial examination of this baby was presented with the connection of her upper and lower eyelids of both eyes by some tissue bands (Figure 1).

This baby was considered as bilateral AFA. Then we had fully physical examination. A high palate arch and penetrating palm at her left hand were found. Systolic murmurs of grade 4 were found at left sternal border. Other physical exam was benign. There was no family history of congenital anomalies or consanguinity. 
The adhesions of the eyelids were divided one day after birth by ophthalmologist without anaesthesia. Subsequent examination showed normal eyelid during follow-up appointments (Figure 2). Echocardiography showed interventricular septal defect $(3.7 \mathrm{~mm})$, atrial septal defect $(2.7 \mathrm{~mm})$, and patent ductus arteriosus $(2 \mathrm{~mm})$. Retinopathy of prematurity (ROP) screen was normal. Peripheral blood chromosome analysis revealed a normal female karyotype. During follow-up appointments, she was in normal development.

The mother is a 43-year-old G2P1 mother with an artificial abortion at 18 years ago. She is a carrier of hepatitis $B$ virus but other serology tests were protected. The current pregnancy was complicated by intrahepatic cholestasis of pregnancy (ICP) at 31+ weeks of gestation without medications. She took some traditional Chinese medicines at 20+weeks of gestation age due to a cold. (Eyelids remain fused until the $5^{\text {th }}$ to $7^{\text {th }}$ month of gestation, maybe the AFA was associated with the medicines or the virus).

\section{Discussion}

Aetiology of AFA is still not fully understood, but failure of separation of the eyelids during eyelid development has been suggested. From an epidemiological point of view, AFA was reported to happen to identical twins and babies of consanguineous marriage couples, ${ }^{1,2}$ and characterized by family hereditary to some degree. Many of them were reported to be associated with TP63-related disorders (Ankyloblepharon-ectodermal defects-cleft lip/palate syndrome). ${ }^{3}$ The ectodermal defects are often referred, because AFA sometimes is associated with wiry hair, pigmentary changes of skin and nail changes. The eyelids of foetus remain fused until the fifth month of gestation. Thus, many factors including infections, drugs and radiations during early pregnancy could probably disturb the separation of eyelids. In this case, HBV infection, cold and medications during her early pregnancy probably contributed to the abnormalities of the baby.

Rosenman classified AFA into four subgroups in 1980, ${ }^{4}$ group 1: sporadic AFA without any associated defects and particular genetic pattern; group 2: AFA is associated with cardiac defects (such as ventricular septal defects and patent ductus arteriosus), ${ }^{4,5}$ gastrointestinal (imperforate anus) or central nerves system defects (hydrocephalus and/or meningomyelocele); ${ }^{6}$ group 3: AFA is associated with ectodermal malformation syndromes such as popliteal pterygium syndrome, ${ }^{7}$ CHAND syndrome (acronym for curly hair, ankyloblepharon, nail dysplasia); group 4: AFA is associated with cleft lip and/or palate defects in the patient or in the extended family (Hay-Wells syndrome). ${ }^{3}$ Recent literatures documented many associated defects in AFA babies which were not included in the above classified groups and suggested a fifth group of AFA characterized by being associated with chromosomal abnormalities (trisomy18, complex chromosome rearrangements). ${ }^{8}$ Group 6 of AFA is also proposed as isolated AFA with a family history of AFA which manifests an autosomal dominant pattern of inheritance. ${ }^{9}$ Other associated defects such as bilateral syndactyly, infantile glaucoma, iridogoniodysgenesis, hypopigmentation, oral synechia were also found in AFA babies, ${ }^{10}$ and perhaps classification of AFA needs to be reconsidered.

Generally, AFA is a solitary malformation of sporadic occurrence. To avoid impaired vision or amblyopia which could be secondary to AFA, it needs an eyelid separation as early as possible. It should be worth noting that AFA sometimes is a manifestation of systemic malformations, especially for many kinds of well-defined syndromes mainly involving in skin, cardiac, neurological, genitourinary and even genetic anomalies. For the corresponding doctors, we should consider a careful physical examination even chromosome examination to avoid missing any abnormalities.

\section{Conclusion}

AFA is a manifestation of systemic malformations. It's worth noting that sometimes it is associated with some welldefined syndromes.

\section{References}

1. Howe J, Harcourt B. Ankyloblepharon filiforme adnatum affecting identical twins. $\mathrm{Br} J$ Ophthalmol. 1974;58(6):630-632.

2. Kuruvilla SE, Simha AR. A rare variant of ankyloblepharon filiforme adnatum associated with skin hypopigmentation: A case report from South India. Indian J Ophthalmol. 2016;64(3):241-243.

3. Guo $S$, Chen $R, X u Y$, et al. Ankyloblepharon-Ectodermal Defects-Cleft Lip/Palate Syndrome. J Craniofac Surg. 2017;28(4):e349-e351.

4. Rosenman $\mathrm{Y}$, Ronen $\mathrm{S}$, Eidelman $\mathrm{Al}$, et al. Ankyloblepharon filiforme adnatum: congenital eyelidband syndromes. Am J Dis Child. 1980;134(8):751-753.

5. Kuruvilla SE, Simha AR. A rare variant of ankyloblepharon filiforme adnatum associated with skin hypopigmentation: A case report from South India. Indian J Ophthalmol. 2016;64:241-243.

6. Kazarian EL, Goldstein P. Ankyloblepharon filiforme adnatum with hydrocephalus, meningomyelocele, and 
imperforate anus. Am J Ophthalmol. 1977;84(3):355357.

7. Pandya A, Bharucha BA, Patwardhan SD, et al. A multiple malformations syndrome with cleft lip and palate and ankyloblepharon filiforme adnatum. Indian J Pediatr. 1985;52(419):667-670.

8. Bacal DA, Nelson LB, Zackai EH, et al. Ankyloblepharon filiforme adnatum in trisomy 18. J Pediatr Ophthalmol Strabismus. 1993;30(5):337-339.

9. Williams MA, White ST, McGinnity G. Ankyloblepharon filiforme adnatum. Arch Dis Child. 2007;92(1):73-74.

10. Lima LB, Barbosa de Paulo LF, Silva CJ, et al. Congenital oral synechia and ankyloblepharon filiforme adnatum: Case report and literature review. Int J Pediatr Otorhinolaryngol.

2016;90:196-199. doi:10.1016/j.ijporl.2016.09.023.

\section{ACKNOWLEDGEMENTS}

We thank Dr. Yuan Xu for the ophthalmologic operation of the baby.

\section{PEER REVIEW}

Not commissioned. Externally peer reviewed.

\section{CONFLICTS OF INTEREST}

The authors declare that they have no competing interests.

\section{FUNDING}

None

\section{PATIENT CONSENT}

The authors, Ling Z, Rong J, declare that:

1. They have obtained written, informed consent for the publication of the details relating to the patient(s) in this report.

2. All possible steps have been taken to safeguard the identity of the patient(s).

3. This submission is compliant with the requirements of local research ethics committees.

Figure 1: Photograph of both eyes of the AFA baby showing full fusion of the eyelids
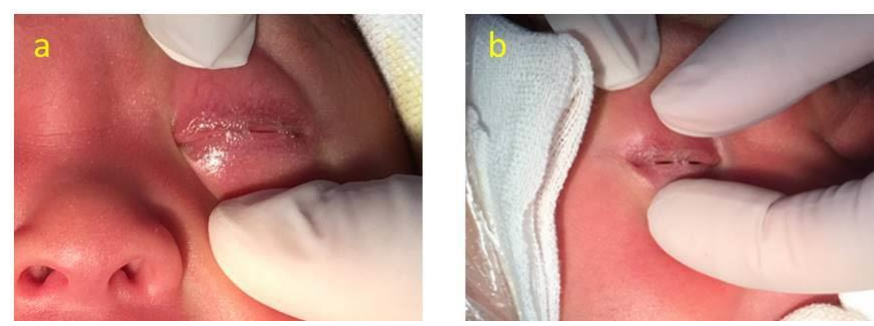

Figure 2: a. both eyes after adhesion separation; b. after 4 weeks after adhesion separation
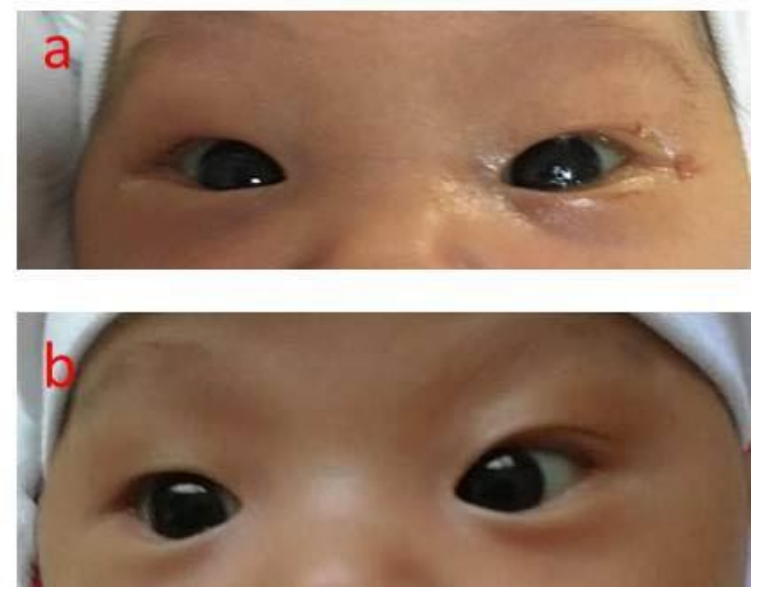